\title{
The influence of functional pinealectomy and exogenous melatonin application on healing of a burr hole in adult rat calvaria: a histological and immunohistochemical study
}

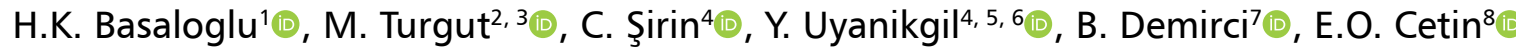 \\ ${ }^{1}$ Department of Histology and Embryology, Adnan Menderes University, Faculty of Medicine, Aydın, Turkey \\ 2Department of Neurosurgery, Adnan Menderes University, Faculty of Medicine, Aydın, Turkey \\ ${ }^{3}$ Department of Histology and Embryology, Adnan Menderes University, Health Sciences Institute, Aydın, Turkey \\ ${ }^{4}$ Department of Histology and Embryology, Ege University, Faculty of Medicine, Izmir, Turkey \\ ${ }^{5}$ Department of Stem Cell, Ege University, Health Science Institute, Izmir, Turkey \\ ${ }^{6}$ Cord Blood, Cell and Tissue Research and Application Centre, Ege University, Izmir, Turkey \\ 'Department of Pharmacology, Adnan Menderes University, Faculty of Medicine, Aydın, Turkey \\ ${ }^{8}$ Department of Pharmaceutical Technology, Department of Biopharmaceutics and Pharmacokinetics, \\ Ege University Faculty of Pharmacy, Izmir, Turkey
}

[Received: 20 March 2021; Accepted: 19 April 2021; Early publication date: 6 May 2021]

\begin{abstract}
Background: Even today, repair of the cranial defects still represents a significant challenge in neurosurgery and various options have been used for their reconstruction to date. However, there are very few studies investigating the effects of exogenous administration of melatonin (MEL) as an agent that promotes bone regeneration. The goal of this study was to investigate the effects of functional pinealectomy $(P x)$ and exogenous MEL administration on the bone repair properties and surrounding connective tissue alterations in a rat calvaria model.

Materials and methods: The total of 30 adult female Wistar-Albino rats was randomly divided into three groups $(n=10)$ : control group (CO; $12 \mathrm{~h}$ light $/ 12 \mathrm{~h}$ dark exposure), functional $P x$ group (24 h light exposure, light-induced functional $P_{x}$ ), and PX+MEL group (light-induced Px + MEL, $20 \mathrm{mg} / \mathrm{kg} /$ day for 12 weeks). Critical-sized burr-hole defects (diameter: $3.0 \mathrm{~mm}$ ) were surgically created by a single operator in the calvarium of all rats, using an electric drill. Animals in $P x+M E L$ group received MEL $20 \mathrm{mg} / \mathrm{kg} /$ day for 12 weeks. At the end of the study, bone healing and connective tissue alterations surrounding drilled defect area in the rat calvaria were determined in haematoxylin-eosin-stained and Mallory Azan slices applied in anti-bone sialoprotein. Image Pro Express 4.5 programme was used for histomorphometric calculation of areas of new bone and fibrotic tissue. Normality control was performed by Shapiro-Wilk test. Variance homogeneities were examined by Shapiro-Wilk and Levene tests; Tukey HSD test was used as a post hoc method since there was no homogeneity problem. All hypothesis tests were performed at the 0.05 significance level.

Results: Histological analysis showed that the bone repair process in the PX+MEL group was similar to that of the CO group, whereas the functional Px group showed a delay. Histomorphometrically, it was found that the Px group had the largest hole diameter and the most fibrotic scar area, although no binary statistical significance was found between the CO and Px+MEL groups $(p=0.910)$.
\end{abstract}

Address for correspondence: E.O. Cetin, PhD, Ege University Faculty of Pharmacy, Department of Pharmaceutical Technology, Department of Biopharmaceutics and Pharmacokinetics, 35100 Bornova, Izmir, Turkey, tel: +90 232 3905908, fax: +90 2323422142, e-mail: emel.oyku.cetin@ege.edu.tr

This article is available in open access under Creative Common Attribution-Non-Commercial-No Derivatives 4.0 International (CC BY-NC-ND 4.0) license, allowing to download articles and share them with others as long as they credit the authors and the publisher, but without permission to change them in any way or use them commercially. 
In terms of vascularisation, it was observed that the most vascular structure was found in the PX+MEL group among the scar tissue and ossification areas, while the vascularisation was the least in the Px group $(p<0.001)$.

Conclusions: Our findings revealed that bone repair process was impaired in functional Px group, but exogenous MEL replacement was able to restore this response. Thus, it is concluded that utilisation of MEL may improve the bone repair in calvarial defects. (Folia Morphol 2022; 81, 2: 271-279)

Key words: bone regeneration, calvaria, melatonin, pinealectomy, rat

\section{INTRODUCTION}

Bone healing, also called bone turnover or restoration of the bone microarchitecture, after various acquired defects or congenital deformities of the cranium, such as traumatic injuries, congenital deformities, decompressive craniectomies, or bone flap loss due to infections still represents a significant challenge in neurosurgery. Although numerous studies have been conducted to develop biomaterials displaying osteoconductive and/or osteoinductive properties to date, utilisation of autogenous bone for repair of the cranial defects seems to be the most appropriate option, possibly due to its biosafety and cost advantage [29]. However, risks of additional morbidity to the patient related to obtaining the graft and resorption of the autogenous bone grafts limit their utilisation in the repair of the cranial defects. As a result, there is still no consensus on which agent to be used in cranioplasty is better in reconstruction of the cranial defects in humans. To improve the bone regeneration and quality of the bone, therefore, use of various agents such as topical or systemic application of growth factors, cytokines and melatonin (MEL) has attracted the attention of scientists [3-5, $7-9,14,16,21,22,25,26,30,33-37]$.

In normal remodelling cycle of the bone, which is balanced between bone-forming osteoblasts and bone resorbing osteoclasts, the resorption phase is followed by bone formation phase, including osteoid formation and then mineralisation $[1,2,10]$. In recent years, it has been reported that MEL can have a pivotal role in this process when age-related osteoporosis is manifested, possibly due to an imbalance in bone turnover related to decreased level of the circulating MEL hormone; thus, MEL could act as an autacoid or a local growth factor for the bone cells $[4,6,7,30,36]$. Importantly, it has also been reported that the proliferation of osteoblasts and the expression of type I collagen and biochemical markers of bone turnover, including bone sialoprotein (BSP) are also promoted by MEL $[7,9,17,25,26,35]$. Despite promising results, however, very few studies have been conducted to investigate the effects of exogenous administration of MEL as an agent that promotes bone regeneration to date and there is still no consensus on which agent to be used in cranioplasty is better in reconstruction of the cranial defects in humans.

In this experimental study, our main purpose was to investigate the effects of exogenous MEL administration on bone healing and connective tissue alterations surrounding the bone defect histopathologically after production of a burr hole in the calvarium of the rats exposed to functional pinealectomy (Px).

\section{MATERIALS AND METHODS}

In this study, 30 adult $200 \mathrm{~g}$ female Wistar-Albino rats were used. The experimental protocol was approved by the Ethical Committee of Aydın Adnan Menderes University (HADYEK 64583101/2014/063). Animals were housed in rat cages in standard conditions ( $24 \pm 2^{\circ} \mathrm{C}$ and $50 \pm 5 \%$ humidity), exposed to 12:12-h light/dark cycle, fed with standardised rodent chow and tap water ad libitum.

The rats were divided into three groups, with 10 animals per group. The first group of animals formed the control group (CO), which was exposed to 12:12-h light/dark cycle. The second and third groups were exposed to 24-h continuous light for 12 weeks in order to produce light-induced functional Px, as described in a previous study [23]. Next, all rats underwent ketamine/xylasine ( 50 and $5 \mathrm{mg} / \mathrm{kg}$, respectively) anaesthesia, and a burr hole (diameter: $3.0 \mathrm{~mm}$ ) was produced using an electric drill (CLASS Mini Grinder sets, PRC) on the right side of the calvarium. Then the wound was closed (Fig. 1). The animals in the second and third groups were moved back to the continuous light-burning room; meanwhile exogenous MEL treatment $(\mathrm{Px}+\mathrm{MEL})$ was applied to only the third group. 

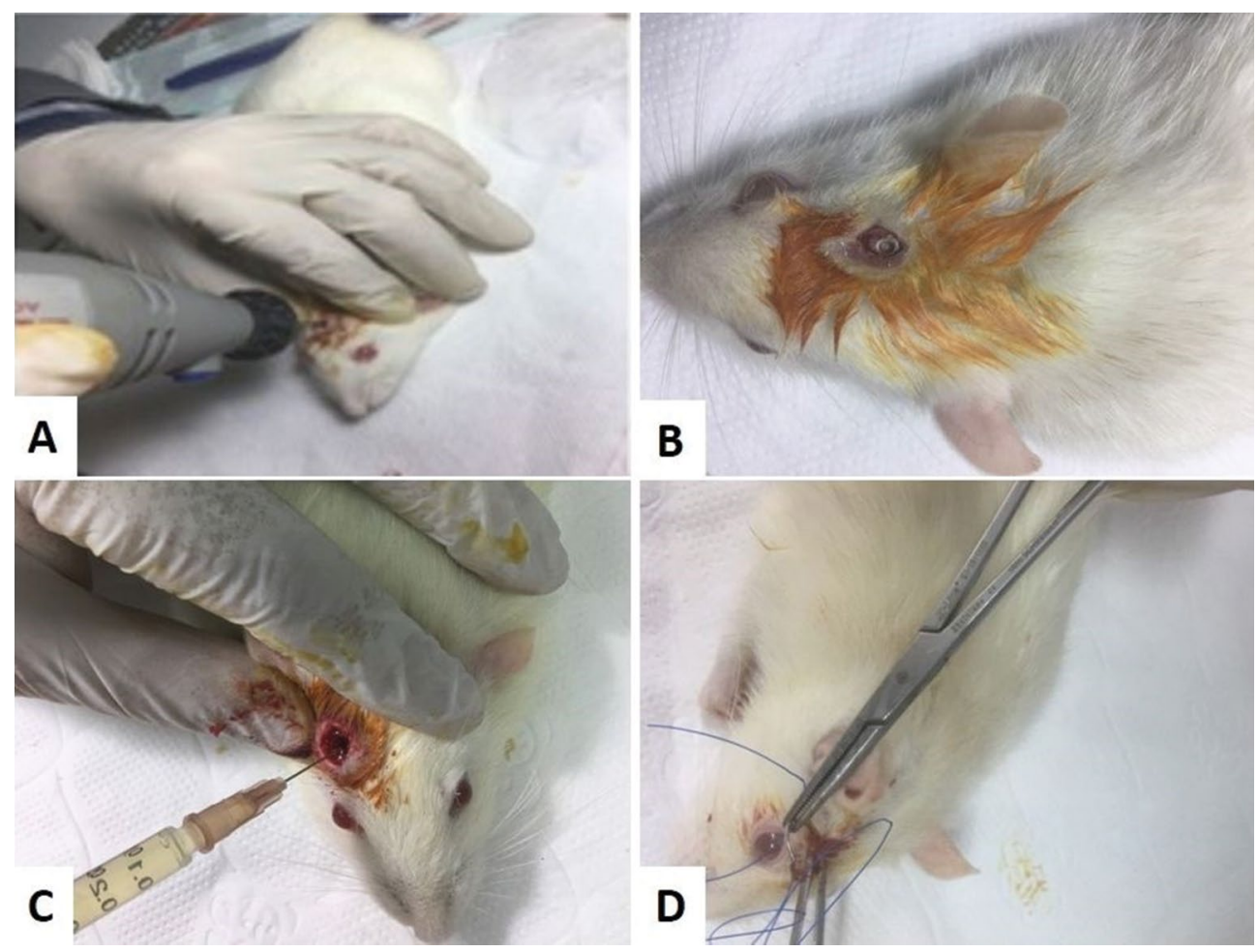

Figure 1. The process of establishing the animal model of bone defect as burr hole on the right side of the rat calvarium using a drill with $3 \mathrm{~mm}$ in diameter.

Melatonin (N-acetyl-5-methoxytryptamine, cat. no: M-5250, Sigma Chemical Co., St. Louis, MO, USA) was first dissolved in pure ethanol and kept in $-20^{\circ} \mathrm{C}$. The second dilution of this stock was freshly prepared in saline to have $5 \%$ ethanol concentration [13]. In the third group, $20 \mathrm{mg} / \mathrm{kg} /$ day of MEL was given intraperitoneally as a single injection for 12 weeks.

At the end of 12 weeks, all the rats were decapitated under the ketamine/xylasine (50 and $5 \mathrm{mg} / \mathrm{kg}$, respectively) anaesthesia. The calvarial area which underwent the burr hole operation was removed for further histological study.

\section{Histological examination of calvaria}

Following sacrification, calvaria were collected into $10 \%$ formalin solution for at least $24 \mathrm{~h}$ before placement in decalcification solution containing $10 \%$ formaldehyde and $20 \%$ formic acid for 2 months, softening of the tissue was controlled by punching irregularly. Tissues were embedded to block in blue-beaded paraffin solution after processing in alcohol and xylol series. $5 \mu \mathrm{m}$ sections were obtained by Leica RM 2145 microtome, transferred to water bath at $45^{\circ} \mathrm{C}$ and microwaved to ensure adhesion and to remove any paraffin remaining. Haematoxylin and eosin (H\&E), Mallory Azan staining and anti-BSP (bs-4729R, Bioss, 1:100) were applied to the related calvarial area and the surgical specimens were evaluated at 10-20× magnification using an Olympus C5050 camera attached to Olympus BX51 light microscope.

\section{Histomorphometry}

For histomorphometric analysis, counting and measurements were made for hole diameter, fibrotic scar areas, ossification areas and number of vessels in the sections taken from calvaria samples from each subject in the experimental groups [15, 18, 42]. Measurement for new ossification areas and fibrotic scar areas was calculated in square micrometres $\left(\mu \mathrm{m}^{2}\right)$ using Image Pro Express 4.5 (Media Cybernetics, Inc., Rockville, MD, USA) programme.

\section{Statistical analysis}

Data analysis was carried out in IBM SPSS (Statistical Package for Social Sciences) Statistics for Windows, Version 25.0 (IBM Corp. Released 2017, Armonk, NY) package programme. Group comparisons were performed using one-way analysis of variance method. Normality control was performed by Shapiro-Wilk test 

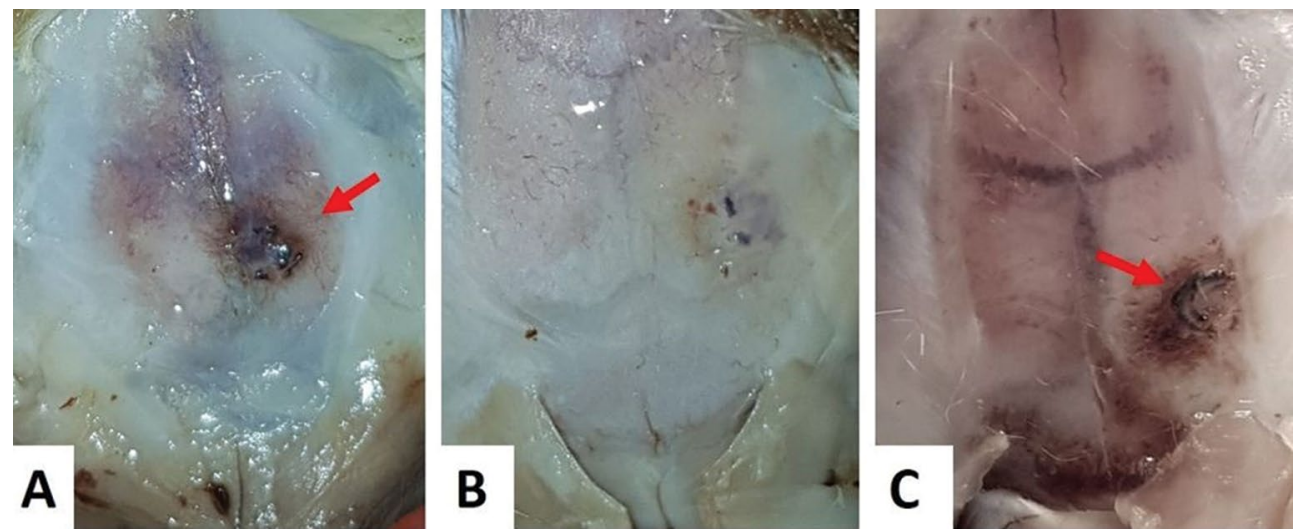

Figure 2. Demonstration of the experimentally produced bone lesions in all rat groups; A. Control (CO) group; B. Pinealectomy (Px) group; C. Pinealectomy plus melatonin (Px+MEL) group.
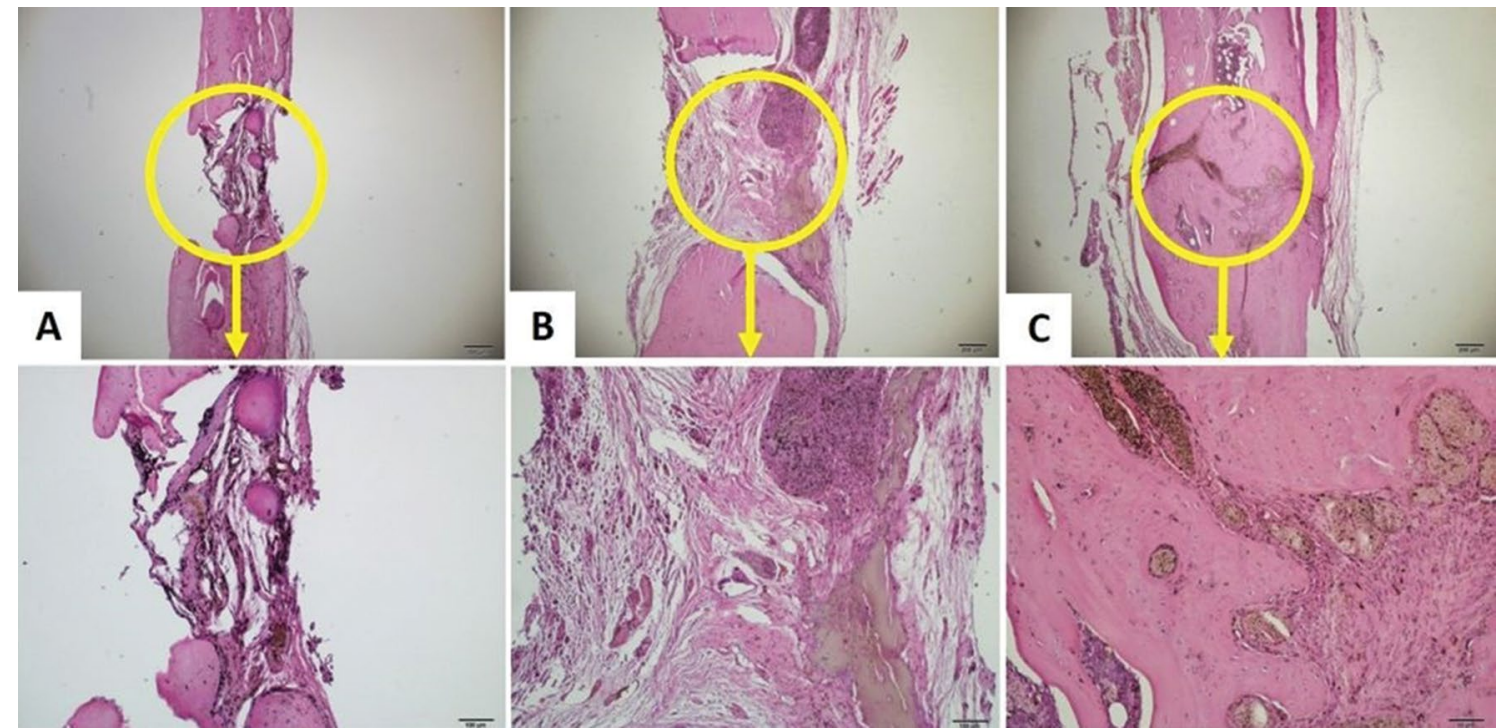

Figure 3. Microscopic evaluation of all groups; A. Control (CO) group; B. Pinealectomy (Px) group; C. Pinealectomy plus melatonin (Px+MEL) group.

that obtained from estimated error. Since there was no problem of adaptation to normal distribution, the study continued with one-way analysis of variance. Variance homogeneities were examined by Levene test; Tukey HSD test was used as a post hoc method, since there was no homogeneity problem. All hypothesis tests were performed at the 0.05 significance level, thus $p<0.05$ was considered significant.

\section{RESULTS}

\section{Macroscopic examination}

When the skin on the calvarium was dissected, drilled holes were detected on the bone and these closed holes were observed macroscopically (Fig. 1). It was found that the scar tissue in the Px+MEL samples were closer to normal when compared with the other two groups (Fig. 2).

\section{Microscopic examination}

In the microscopic sections, the orientation of the hole in the bone was adjusted and serial sections were taken. These sections were stained in H\&E and Mallory Azan in order to show the general structure and were applied in anti-BSP immunohistochemistry. Histologically, the holes were found in the sections. Importantly, it was found that these hole structures were filled with irregular dense connective tissue called fibrotic in both control group and Px group (Fig. 3). 

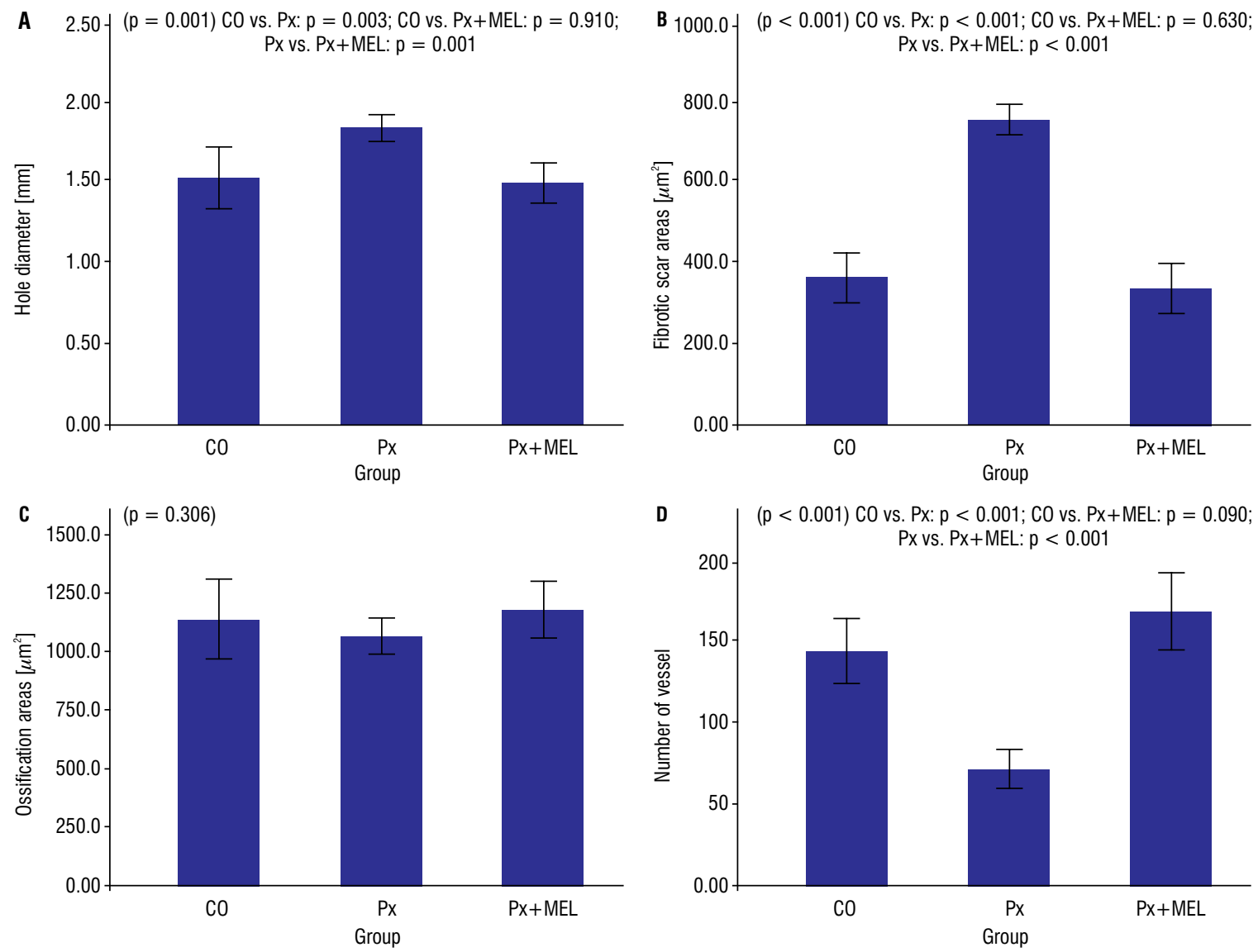

Figure 4. Statistical evaluation graph of histomorphometric analysis. Graphical representation of hole diameter (A), fibrotic scar area (B), ossification area (C) and number of vessels (D) in all groups; $\mathrm{CO}$ - control group; $\mathrm{Px}$ - pinealectomy; MEL — melatonin.

When the hole diameters were evaluated statistically, it was seen that the Px group had the largest hole diameter. No statistical significance was found in the comparison of the groups with each other (Fig. 4A). When evaluated in terms of fibrotic scar area, it was calculated that the most scar area was in the Px group, although no binary statistical significance was found between the CO and Px+MEL groups. Importantly, a statistical significance was found when comparing these two groups with the Px group ( $p<0.001$ ) (Fig. 4B). When evaluated in terms of ossification areas, it was observed that the most ossification was in the $\mathrm{Px}+\mathrm{MEL}$ group, while the highest ossification was found in the Px group. However, there was no statistical significance between the groups ( $p=0.306$ ) (Fig. 4C). In terms of vascularisation, it was observed that the most vascular structure was found in the Px+MEL group among the scar areas and ossification areas, while the vascularisation was the least in the Px group. When the $\mathrm{CO}$ and Px groups were compared, a statistically significant reduction was observed $(p<0.001)$.
There was also a statistical significance difference between Px and Px+MEL groups ( $p<0.001$ ) (Fig. 4D).

When this connective tissue structure was examined at larger magnification, it was found that it contains fibroblast-like cells and type I collagen bundles. In Px group, however, new bone splices were found that they were localised to different sites located within the connective tissue, possibly formed by intramembranous ossification. More importantly, in Px+MEL group, it was noted that this connective tissue area was small and ossification developed in most of the structure. With this appearance, it was the experimental group, which was closest to the normal histological structure of the other groups. Mallory Azan staining showed that the type I collagen bundles were stained blue while the newly formed bone areas were red (Fig. 5).

\section{DISCUSSION}

This experimental study evidenced that MEL replacement is related to the improvement of bone healing, 

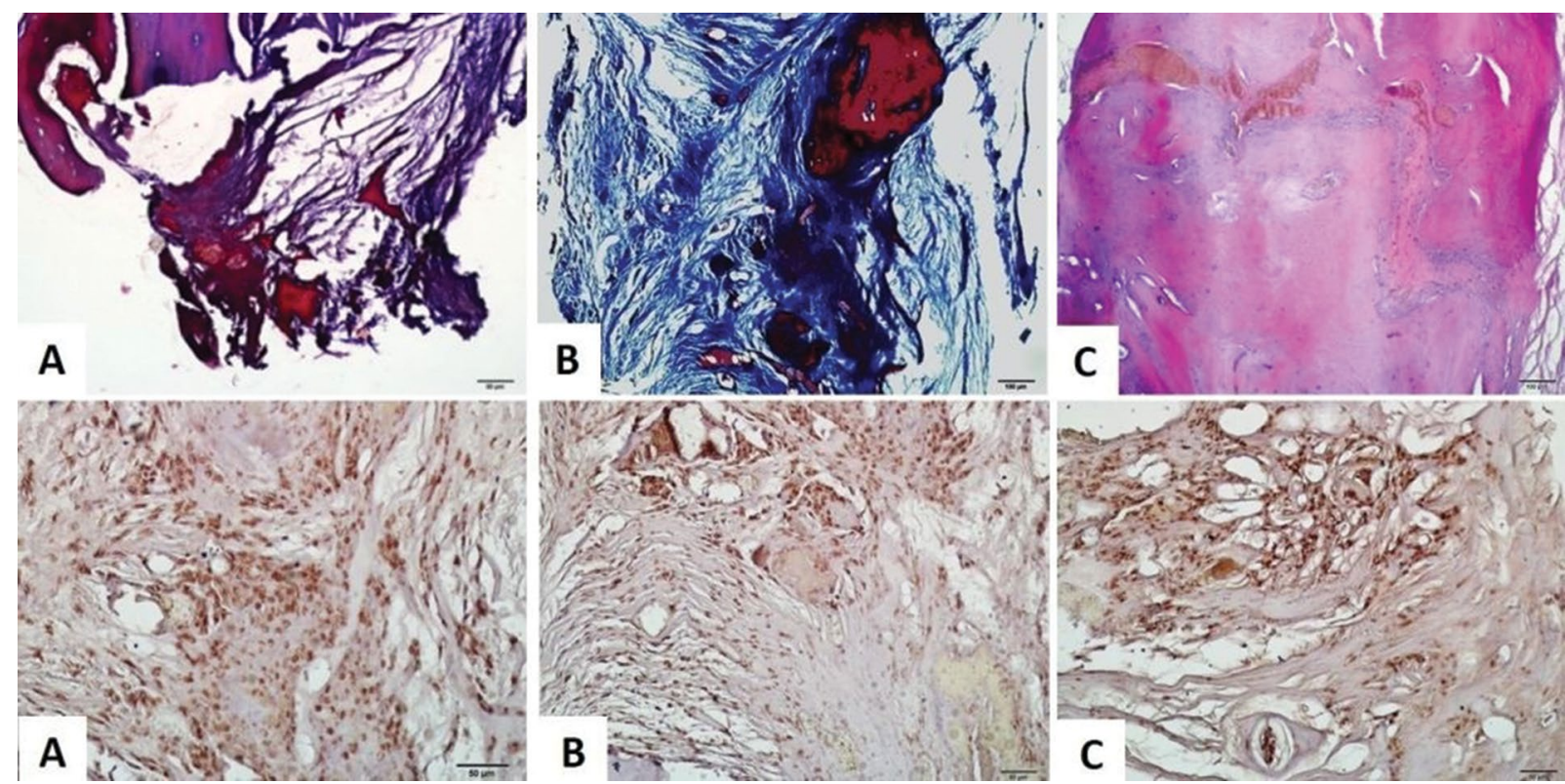

Figure 5. Microscopic evaluation of all groups; A. Control (CO) group; B. Pinealectomy (Px) group; C. Pinealectomy plus melatonin (Px+MEL) group.

in contrast to functional Px group, possibly due to increased osteoblastic activity and modulation of connective tissue alterations surrounding the bone defect driven by exogenous MEL administration in adult rats.

Previous studies reported that matrix cellular proteins, such as BSP, also called SPARC or BM40, osteopontin, tenascin $C$, and thrombospondin-1 and -2 , were the critical regulators of bone healing process $[1,10]$. BSP is composed of mineralised tissues such as bone, dentin, cementum and calcified cartilage. It binds to hydroxyapatite crystals and an integral part of the mineral matrix in bone tissue. Now, it is known to be an important component of the extracellular matrix of bone and forms all non-collagen proteins found in bone and cementum. In our study, the cell characterisation of the osteoblast lineage was via immunostaining for BSP. The $\mathrm{CO}$ and $\mathrm{Px}+\mathrm{MEL}$ groups are similar in terms of BSP, both groups have a high level of immune reaction. A lower degree of immunoreaction was detected in the Px group.

Several studies documented that MEL had been linked to osteoblastic differentiation and bone metabolism $[4,6,30,36]$. In a previous study, Witt-Enderby et al. (2006) [41] demonstrated that MEL influences bone cell precursors in rat bone marrow which has high concentrations of MEL. Koyama, et al. (2002) [14] showed that the administration of pharmacological doses of MEL during the growth of young rats increased the bone mass through the inhibition of bone resorption.
To date, however, the role of MEL replacement has not yet been widely evaluated in adult animals with lower production of endogenous MEL, as did in our functional Px group. In this study, we intended for investigation its role on bone healing; therefore we applied a functional Px rat model to evaluate the effect of exogenous MEL administration histopathologically [23].

Experimental studies revealed that action of exogenous and endogenous MEL upon bone tissue is due to an increased osteoblastic activity, a decreased osteoclastic activity, and an increased osteoclastogenesis inhibitory factor, also known as osteoprotegerin, thus increasing its mass $[14,19,20,33,40]$. In addition to its stimulating effect on bone metabolism and production of type I collagen, inhibitory effect on proteasomes has also been suggested [14, 19, $20,33,40]$. Thus, promotion of bone healing by MEL could be related to one or more of the following possible mechanisms: the promotion of the osteoblast differentiation and/or activity, an increased expression of the osteoprotegerin by osteoblasts, resulting with a decreased differentiation of osteoclasts, and increased scavenging of free radicals which were generated by osteoclasts [31]. Further, and more specifically, it has been speculated that MEL interferes with bone healing in several ways: through modulation of oxidative stress [27, 28, 32], collagen fibril formation [19], differentiation of osteoblasts via PDGF/AKT signalling pathway $[9,25$, 
$26,35,43]$, or activity of osteoblasts and osteoclasts via MEL-MT2 receptor pathway $[9,34,41]$ or RANK/ /NF- $\kappa$ B signalling pathway $[14,26]$ or $\mathrm{Wnt} / \beta$-catenin signalling pathway $[16,25,40]$. Moreover, MEL has also been found to stimulate gene expression of BSP and other bone marker proteins including alkaline phosphate, secreted protein, osteocalcin and osteopontin [30].

Despite accumulating evidence about the effects of MEL upon regeneration of the bone tissue during the last decades, its use for cranial defects has received little attention and to date, healing of the bone after application of MEL has been evaluated in few experimental animal studies using model of calvaria $[9,25,26,35]$. In addition to stimulatory action of MEL related to bone formation, however, possible effects of MEL upon the connective tissue surrounding the cranial defect have been also investigated for the first time in this study. Based on our findings, it is evident that the ossification process is accelerated by the effect of exogenous MEL, while the absence of endogenous MEL also negatively affects ossification.

On the other hand, it has been reported that a lower production of MEL, by some genetic modifications (pineal MEL deficient mice, C57BL/6 and Swiss strains) [12, 34], or various Px techniques (surgical or functional) $[21,22,24,37-39]$ results in alterations in structure, density and mechanical strength of the bone in animals including mice, rat, rabbit, chicken, sheep, and fish [9, 34]. To the best of our knowledge, however, no study was performed to evaluate the healing in endogenous MEL deficiency and exogenous MEL administration, when added to biomaterials or implants [3-6, 36]. Thus, the process of how the absence of endogenous MEL interferes with the bone healing is unclear. Considering this, the purpose of this study was to evaluate the cellular changes that occur in the bone of rats undergoing Px that received or did not receive daily exogenous MEL replacement as a possible therapy for conditions characterised by a decrease in the secretion of this hormone by the pineal gland.

In a previous in vitro study, it has been suggested that exogenous MEL administration has positive effects on both angiogenesis and wound healing [19]. In a recently published paper, Filipowska et al. (2017) [11] also suggested the role of production of vascular endothelial growth factor (VEGF) by either hypertrophic chondrocytes or differentiating mesenchymal cells in bone development and regeneration. In fact, our findings confirm that beneficial effects of MEL on blood vessel invasion for initiation of bone tissue formation, possibly as a result of increased VEGF production by MEL.

Taken together our findings provide an evidence that the absence of MEL delays repair and exogenous MEL replacement regulates this alteration, which would emphasize the role of this neurohormone in bone remodelling, especially in conditions in which a decrease occurs in the circadian release capacity of this hormone by the pineal gland, as did in various clinical disease conditions. Undoubtedly, further understanding of pathological changes in the bone tissue and their reversion is critical for the success of MEL replacement treatment. Two limitations of our study that created an in vivo rat calvaria model are as follows: absence of any analysis for inorganic material content of bone tissue and difference of drilled defects from those in humans in terms of bone remodelling. Also, lack of any imaging study illustrating bone healing and angiogenesis is another limitation of the study. Future studies including imaging are needed for better understanding of modulation of osteoblast and osteoclast function and mineralization with MEL in cases of bone defect that simulates the situation in human.

\section{CONCLUSIONS}

Based on the results of this study, we may notice an interaction in cellular responses and protein activity in the absence of MEL, suggesting that when there is a delay in the production of proteins that stimulate bone formation, ossification because of hormone administration increases vascularisation and may result in less scar tissue formation. The MEL replacement, in most parameters evaluated in this study, showed behaviour very close to that of the $\mathrm{CO}$ group. Therefore, the absence of the pineal gland impairs the bone repair process during osseointegration; however, the daily exogenous MEL replacement was able to partially restore this response. However, the authors believe that further studies should confirm this information in future.

\section{Acknowledgements}

The authors thank to Research Foundation of Aydin Adnan Menderes University (ADU-TPF-15019) for funding of this research. We also thank the anonymous reviewers of the journal "Folia Morphologica" for their constructive comments and help with the manuscript.

Conflict of interest: None declared 


\section{REFERENCES}

1. Alford Al, Hankenson KD. Matricellular proteins: Extracellular modulators of bone development, remodeling, and regeneration. Bone. 2006; 38(6): 749-757, doi: 10.1016/j. bone.2005.11.017, indexed in Pubmed: 16412713.

2. Bilezikian JP, Raisz LG, Rodan GA. Principles of bone biology. 2nd. Academic Press, San Diego 1696.

3. Calvo-Guirado JL, Gómez-Moreno G, Barone A, et al. Melatonin plus porcine bone on discrete calcium deposit implant surface stimulates osteointegration in dental implants. J Pineal Res. 2009; 47(2): 164-172, doi: 10.1111/j.1600-079X.2009.00696.x, indexed in Pubmed: 19570131.

4. Calvo-Guirado JL, Gómez-Moreno G, López-Marí L, et al. Actions of melatonin mixed with collagenized porcine bone versus porcine bone only on osteointegration of dental implants. J Pineal Res. 2010; 48(3): 194-203, doi: 10.1111/j.1600-079X.2009.00743.x, indexed in Pubmed: 20443224.

5. Calvo-Guirado JL, Gómez-Moreno G, Maté-Sánchez JE, et al. New bone formation in bone defects after melatonin and porcine bone grafts: experimental study in rabbits. Clin Oral Implants Res. 2015; 26(4): 399-406, doi: 10.1111/clr.12364, indexed in Pubmed: 24602080.

6. Calvo-Guirado JL, Ramírez-Fernández MP, Gómez-Moreno G, et al. Melatonin stimulates the growth of new bone around implants in the tibia of rabbits. J Pineal Res. 2010; 49(4): 356-363, doi: 10.1111/j.1600-079X.2010.00801.x, indexed in Pubmed: 20666975.

7. Cardinali DP, Ladizesky MG, Boggio V, et al. Melatonin effects on bone: experimental facts and clinical perspectives. J Pineal Res. 2003; 34(2): 81-87, doi: 10.1034/j.1600079x.2003.00028.x, indexed in Pubmed: 12562498.

8. Chaves LH, Giovanini AF, Zielak JC, et al. Growth hormone effects on healing efficacy, bone resorption and renal morphology of rats: histological and histometric study in rat calvaria. Heliyon. 2020; 6(10): e05226, doi: 10.1016/j. heliyon.2020.e05226, indexed in Pubmed: 33102851.

9. Clafshenkel WP, Rutkowski JL, Palchesko RN, et al. A novel calcium aluminate-melatonin scaffold enhances bone regeneration within a calvarial defect. J Pineal Res. 2012; 53(2): 206-218, doi: 10.1111/j.1600-079X.2012.00989.x, indexed in Pubmed: 22462771.

10. Delany AM, Hankenson KD. Thrombospondin-2 and SPARC/ osteonectin are critical regulators of bone remodeling. J Cell Commun Signal. 2009; 3(3-4): 227-238, doi: 10.1007/ s12079-009-0076-0, indexed in Pubmed: 19862642.

11. Filipowska J, Tomaszewski KA, Niedźwiedzki $Ł$, et al. The role of vasculature in bone development, regeneration and proper systemic functioning. Angiogenesis. 2017; 20(3): 291-302, doi: 10.1007/s10456-017-9541-1, indexed in Pubmed: 28194536.

12. Gómez-Corvera A, Cerrillo I, Molinero P, et al. Evidence of immune system melatonin production by two pineal melatonin deficient mice, C57BL/6 and Swiss strains. J Pineal Res. 2009; 47(1): 15-22, doi: 10.1111/j.1600079X.2009.00683.x, indexed in Pubmed: 19522737.

13. Kerem $\mathrm{H}$, Akdemır $\mathrm{O}$, Ates $\mathrm{U}$, et al. The effect of melatonin on a dorsal skin flap model. J Invest Surg. 2014; 27(2): 57-64, doi: 10.3109/08941939.2013.835892, indexed in Pubmed: 24063690.
14. Koyama H, Nakade O, Takada Y, et al. Melatonin at pharmacologic doses increases bone mass by suppressing resorption through down-regulation of the RANKL-mediated osteoclast formation and activation. J Bone Miner Res. 2002; 17(7): 1219-1229, doi: 10.1359/jbmr.2002.17.7.1219, indexed in Pubmed: 12096835.

15. Li J, Jin L, Wang M, et al. Repair of rat cranial bone defect by using bone morphogenetic protein-2-related peptide combined with microspheres composed of polylactic acid/polyglycolic acid copolymer and chitosan. Biomed Mater. 2015; 10(4): 045004, doi: 10.1088/17486041/10/4/045004, indexed in Pubmed: 26154695.

16. Li X, Li Z, Wang J, et al. Wnt4 signaling mediates protective effects of melatonin on new bone formation in an inflammatory environment. FASEB J. 2019; 33(9): 10126-10139, doi: 10.1096/fj.201900093RR, indexed in Pubmed: 31216173.

17. Liu J, Huang F, He HW. Melatonin effects on hard tissues: bone and tooth. Int J Mol Sci. 2013; 14(5): 10063-10074, doi: 10.3390/ijms140510063, indexed in Pubmed: 23665905.

18. Liu W, Kang N, Seriwatanachai D, et al. Chronic kidney disease impairs bone defect healing in rats. Sci Rep. 2016; 6(1): 23041, doi: 10.1038/srep23041, indexed in Pubmed: 26955758.

19. Nakade $\mathrm{O}$, Koyama $\mathrm{H}$, Ariji $\mathrm{H}$, et al. Melatonin stimulates proliferation and type I collagen synthesis in human bone cells in vitro. J Pineal Res. 1999; 27(2): 106-110, doi: 10.1111/j.1600-079x.1999.tb00603.x, indexed in Pubmed: 10496146.

20. Ohlsson C, Bengtsson BA, Isaksson OG, et al. Growth hormone and bone. Endocr Rev. 1998; 19(1): 55-79, doi: 10.1210/edrv.19.1.0324, indexed in Pubmed: 9494780.

21. Ostrowska Z, Kos-Kudla B, Marek B, et al. The influence of pinealectomy and melatonin administration on the dynamic pattern of biochemical markers of bone metabolism in experimental osteoporosis in the rat. Neuro Endocrinol Lett. 2002; 23 Suppl 1: 104-109, indexed in Pubmed: 12019362.

22. Ostrowska Z, Kos-Kudla B, Nowak M, et al. The relationship between the daily profile of chosen biochemical markers of bone metabolism and melatonin and other hormone secretion in rats under physiological conditions. Neuro Endocrinol Lett. 2002; 23(5-6): 417-425, indexed in Pubmed: 12500163.

23. Özkaya M, Gündoğdu A, Seyran M, et al. Effect of exogenous melatonin administration on pain threshold in exercise trained rats under light-induced functional pinealectomy. Biol Rhythm Res. 2014; 45(6): 849-859, doi: 10.1080/09291016.2014.923619.

24. Pawlicki B, Henry BM, Tomaszewski KA, et al. Neonatal pinealectomy in rats: a simple micro-suction technique. Folia Med Cracov. 2017; 57(1): 39-46, indexed in Pubmed: 28608861.

25. Ping Z, Hu X, Wang L, et al. Melatonin attenuates titanium particle-induced osteolysis via activation of $\mathrm{Wnt} / \beta$-catenin signaling pathway. Acta Biomater. 2017; 51: 513-525, doi: 10.1016/j.actbio.2017.01.034, indexed in Pubmed: 28088671

26. Ping Z, Wang Z, Shi J, et al. Inhibitory effects of melatonin on titanium particle-induced inflammatory bone resorption and osteoclastogenesis via suppression of NF- $\kappa$ B sig- 
naling. Acta Biomater. 2017; 62: 362-371, doi: 10.1016/j. actbio.2017.08.046, indexed in Pubmed: 28867647.

27. Ramírez-Fernández MP, Calvo-Guirado JL, de-Val JEM, et al. Melatonin promotes angiogenesis during repair of bone defects: a radiological and histomorphometric study in rabbit tibiae. Clin Oral Investig. 2013; 17(1): 147-158, doi: 10.1007/ s00784-012-0684-6, indexed in Pubmed: 22323056.

28. Reiter RJ, Calvo JR, Karbownik M, et al. Melatonin and its relation to the immune system and inflammation. Ann N Y Acad Sci. 2000; 917: 376-386, doi: 10.1111/j.17496632.2000.tb05402.x, indexed in Pubmed: 11268363.

29. Rogers GF, Greene AK. Autogenous bone graft: basic science and clinical implications. J Craniofac Surg. 2012; 23(1): 323-327, doi: 10.1097/SCS.0b013e318241dcba, indexed in Pubmed: 22337435.

30. Roth JA, Kim BG, Lin WL, et al. Melatonin promotes osteoblast differentiation and bone formation. J Biol Chem. 1999; 274(31): 22041-22047, doi: 10.1074/ jbc.274.31.22041, indexed in Pubmed: 10419530.

31. Sánchez-Barceló EJ, Mediavilla MD, Tan DX, et al. Scientific basis for the potential use of melatonin in bone diseases: osteoporosis and adolescent idiopathic scoliosis. J Osteoporos. 2010; 2010: 830231, doi: 10.4061/2010/830231, indexed in Pubmed: 20981336.

32. Seema R, Chandana H. Melatonin ameliorates oxidative stress and induces cellular proliferation of lymphoid tissues of a tropical rodent, Funambulus pennanti, during reproductively active phase. Protoplasma. 2013; 250(1): 21-32, doi: 10.1007/s00709-011-0367-1, indexed in Pubmed: 22205185

33. Sethi S, Radio NM, Kotlarczyk MP, et al. Determination of the minimal melatonin exposure required to induce osteoblast differentiation from human mesenchymal stem cells and these effects on downstream signaling pathways. J Pineal Res. 2010; 49(3): 222-238, doi: 10.1111/j.1600079X.2010.00784.x, indexed in Pubmed: 20626586.

34. Sharan K, Lewis K, Furukawa T, et al. Regulation of bone mass through pineal-derived melatonin-MT2 receptor pathway. J Pineal Res. 2017; 63(2): e12423, doi: 10.1111/ jpi.12423, indexed in Pubmed: 28512916.

35. Shino $H$, Hasuike A, Arai $Y$, et al. Melatonin enhances vertical bone augmentation in rat calvaria secluded spaces.
Med Oral Patol Oral Cir Bucal. 2016; 21(1): e122-e126, doi: 10.4317/medoral.20904, indexed in Pubmed: 26595835.

36. Tresguerres IF, Tamimi F, Eimar H, et al. Melatonin dietary supplement as an anti-aging therapy for age-related bone loss. Rejuvenation Res. 2014; 17(4): 341-346, doi: 10.1089/rej.2013.1542, indexed in Pubmed: 24617902.

37. Turgut M, Kaplan S, Turgut AT, et al. Morphological, stereological and radiological changes in pinealectomized chicken cervical vertebrae. J Pineal Res. 2005; 39(4): 392-399, doi: 10.1111/j.1600-079X.2005.00263.x, indexed in Pubmed: 16207295.

38. Turgut M, Yenisey C, Bozkurt M, et al. Analysis of zinc and magnesium levels in pinealectomized chicks: roles on development of spinal deformity? Biol Trace Elem Res. 2006; 113(1): 67-75, doi: 10.1385/BTER:113:1:67, indexed in Pubmed: 17114816.

39. Turgut M, Yenisey C, Uysal A, et al. The effects of pineal gland transplantation on the production of spinal deformity and serum melatonin level following pinealectomy in the chicken. Eur Spine J. 2003; 12(5): 487-494, doi: 10.1007/s00586-003-0528-9, indexed in Pubmed: 12687443

40. Vriend J, Reiter RJ. Melatonin, bone regulation and the ubiquitin-proteasome connection: a review. Life Sci. 2016; 145: 152-160, doi: 10.1016/j.lfs.2015.12.031, indexed in Pubmed: 26706287.

41. Witt-Enderby PA, Radio NM, Doctor JS, et al. Therapeutic treatments potentially mediated by melatonin receptors: potential clinical uses in the prevention of osteoporosis, cancer and as an adjuvant therapy. J Pineal Res. 2006; 41(4): 297-305, doi: 10.1111/j.1600-079X.2006.00369.x, indexed in Pubmed: 17014686.

42. Zhang L, Chang M, Beck CA, et al. Analysis of new bone, cartilage, and fibrosis tissue in healing murine allografts using whole slide imaging and a new automated histomorphometric algorithm. Bone Res. 2016; 4: 15037, doi: 10.1038/boneres.2015.37, indexed in Pubmed: 26816658.

43. Zhu G, Ma B, Dong P, et al. Melatonin promotes osteoblastic differentiation and regulates PDGF/AKT signaling pathway. Cell Biol Int. 2020; 44(2): 402-411, doi: 10.1002/ cbin.11240, indexed in Pubmed: 31535749. 